\title{
El papel de las luchas previas en la trayectoria de una empresa pesquera recuperada por sus trabajadores (Necochea, 2004-2011)
}

\author{
María Luciana Nogueira
}

CEIL (Conicet) - GESMar (UNMDP)

nogueiramluciana@gmail.com

Title: The role of previous struggles in the trajectory of a fishing company recovered by its workers (Necochea, 2004-2011)

Resumen: Este trabajo analiza el papel que jugaron las luchas obreras en los años previos al proceso de recuperación de una fábrica pesquera de la ciudad de Necochea. Este conflicto se reconstruyó desde 2004 a 2011 a partir de una multiplicidad de fuentes y se estableció un diálogo entre el mismo y los conceptos de escuela de guerra, de Lenin, y de potencialidad de la clase obrera, de Collado y Roitman. Los resultados obtenidos establecen vínculos entre los conflictos emprendidos durante la gestión patronal y la lucha por la recuperación de la empresa que se expresan en la constitución de un colectivo fabril, la obtención de apoyo por parte de otros sectores de trabajadores, la generación de una "moral de lucha" y el cuestionamiento de la política de división obrera y de la desigualdad en la relación capital-trabajo.

Palabras clave: empresas recuperadas - luchas previas - escuela de guerra

\begin{abstract}
This paper analyzes the role played by workers' struggles in the years prior to the recovery process of a fishing factory in the city of Necochea. This conflict was rebuilt from 2004 to 2011 from a multiplicity of sources and a dialogue was established between it and the concepts of war school (Lenin) and potential of the working class (Collado and Roitman). The results obtained establish links between conflicts undertaken during the patronal management and the struggle for the recovery of the company, which are expressed in the unity of the workers, the obtaining of support from other sectors of workers, the generation of a "fighting moral" and the questioning of the policy of division of the workers' collective and of inequality in the capital-labor relationship.
\end{abstract}

Keywords: recovered factories - previous struggles - war school

(Archivos, año VIII, $\mathrm{n}^{\circ}$ 15, septiembre de 2019, pp. 119-141) 


\section{Planteo inicial del problema e hipótesis general}

Este trabajo partirá de una pregunta relativa a las condiciones de surgimiento y consecución de empresas recuperadas por sus trabajadores, en situaciones de cierre y despidos por parte de la empresa originaria. Muchos estudios se han preguntado por el contexto en que se produjeron las recuperaciones de empresas y el modo en que las mismas se llevaron adelante (Brunet y Pizzi, 2011; Rebón, 2004; Ruggeri, 2009). En esta oportunidad, queremos poner bajo la lupa un elemento que consideramos central a la luz de nuestro trabajo de campo: las experiencias de organización y lucha previas al proceso de recuperación de una empresa pesquera de Necochea. ${ }^{1}$

El enfoque que proponemos retoma una hipótesis de Collado y Roitman que postula que las luchas particulares tienen un "potencial clasista" (2015: 145). Para alcanzar dicho potencial, las autoras refieren que estas luchas deben "trascender el ámbito particular para adquirir una disposición solidaria" (ibídem), lo cual permitiría ampliar paulatinamente el alcance de un programa común, reducir la fragmentación y "religar" a la clase obrera (2015: 149). Aquí proponemos que dicho potencial clasista también puede derivar de las luchas parciales, en tanto las mismas pueden constituirse como reservorio de experiencias para luchas futuras. Su consecución y proceso tienen la potencialidad de actuar en tanto "caja de herramientas" de un acervo de prácticas y de conclusiones, y de constituirse como bagaje de experiencias colectivas que persisten como sedimentos en la memoria obrera (Pérez Álvarez, 2013). Sobre estos sedimentos, entendidos como materiales construidos que decantaron de combates precedentes, es posible reemprender y reconstruir la unidad obrera, las acciones de combate contra el capital y la solidaridad de clase (en términos de establecimiento de intereses y acciones comunes para alcanzar objetivos comunes).

Por ello, relacionamos este potencial clasista del que hablan las autoras con el concepto de "escuela de guerra" de Lenin (2013), quien refiriéndose a las huelgas destacó su carácter pedagógico, posibilitador de enseñanzas y aprendizajes plausibles de ser utilizados a posteriori. Aquí nos basaremos en el concepto de "escuela de guerra" expuesto en el texto "Sobre las huelgas", de 1899, el cual se refiere específicamente a la acción de lucha huelguística. Proponemos extender los alcances de dichas conceptualizaciones a otros formatos de combate obreros, y

1. Ciudad costera localizada al sudeste de la provincia de Buenos Aires (Argentina), a $110 \mathrm{~km}$ de Mar del Plata, en la cual se ubica Puerto Quequén. Cuenta con una población de 86.600 habitantes de acuerdo al último Censo Nacional del año 2010. 
específicamente a los enmarcados en conflictos por cierre, ocupación y recuperación de empresas.

Al abordar la reconstrucción del proceso de lucha que dio lugar a la conformación de La Recuperada, Cooperativa de Industria Pesquera y Alimenticia, en el trabajo de campo detectamos situaciones de lucha precedentes vinculadas con el desarrollo de la recuperación. La indagación sobre conflictos anteriores fue motivada por su referencia espontánea por parte de los propios trabajadores durante las entrevistas efectuadas meses después de conformarse la cooperativa, lo cual mostraba un enlace que ellos mismos establecían entre combates anteriores y la gestión obrera.

A continuación, expondremos una síntesis del caso en cuestión, la metodologia de investigación implementada y las fuentes de información. Seguidamente analizaremos el vínculo entre las luchas previas y la recuperación de la fábrica desde los conceptos de potencial clasista y escuela de guerra. Por último, presentaremos una síntesis de las conclusiones a partir de lo hallado.

\section{La Recuperada, Cooperativa de Industria Pesquera y Alimenticia, en el movimiento argentino de empresas recuperadas}

Nuestro recorrido de investigación sobre empresas pesqueras recuperadas consiste en el abordaje en profundidad de dos casos que acontecieron en la ciudad portuaria de Necochea: La Recuperada y Engraucoop. Ambas se originaron a partir de la quiebra de dos firmas que se radicaron alli durante la década del 70, época dorada del sector industrial pesquero local. Sus procesos de recuperación se iniciaron en el año 2011, luego de cuatro décadas de un progresivo desguace de la industria pesquera local que implicó el cierre de más de 20 plantas de procesamiento de pescado, con la consecuente pérdida de más de 3.000 puestos de trabajo. En el gráfico de página siguiente se muestra la disminución en la cantidad de empresas y puestos de trabajo desde 1970 en adelante.

En esta oportunidad nos centraremos en el caso de La Recuperada, que proviene de Industrial Pesquera S.A., empresa dedicada al procesamiento de pescado fresco para exportación. A partir de diciembre de 2010, en esta unidad productiva acontecieron secuencias típicas de la generalidad de los procesos de recuperación propios de la historia reciente argentina (Ruggeri, 2009: 161): atrasos salariales, retiro inusual de materia prima, anuncio de ingreso a concurso de acreedores, despidos sin indemnizaciones y abandono patronal. Dichas generalidades confluyeron con ciertas particularidades del caso. En primer lugar, esta experiencia se constituyó como la primera empresa recuperada 


\section{Gráfico 1. Desmantelamiento del sector industrial pesquero de Necochea-Quequén entre 1970 y 2012}

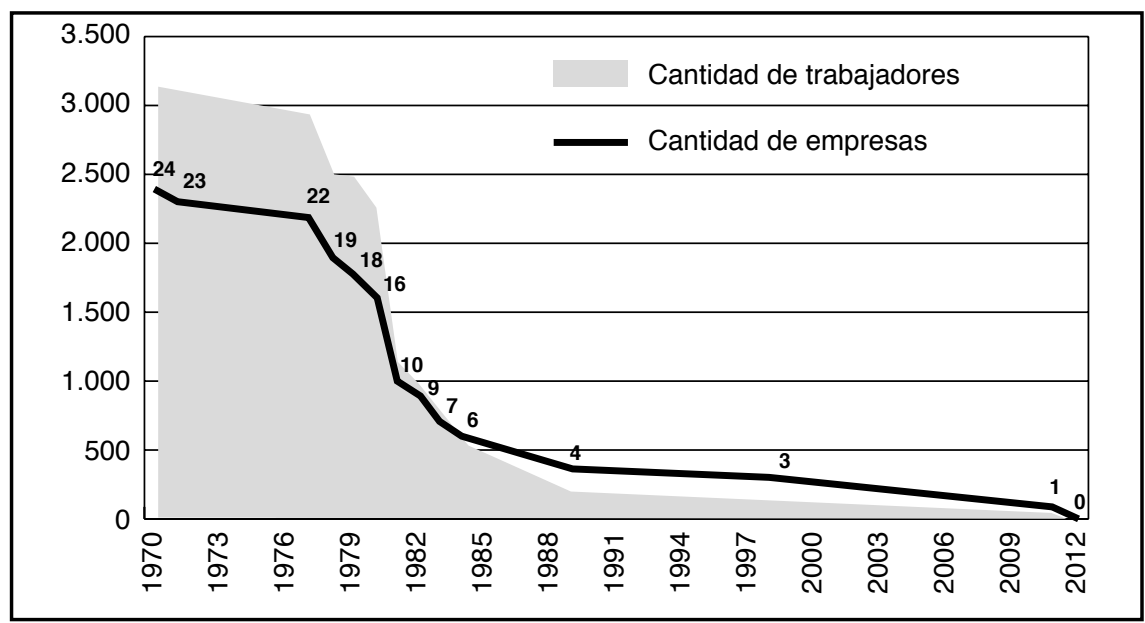

Fuente: Elaboración propia en base al archivo de La Recuperada.

argentina perteneciente al sector industrial pesquero, rubro en el que desde los 90 predominaba el gran capital concentrado y transnacional, cuyos correlatos fueron el cierre de cientos de pequeñas y medianas empresas en la provincia de Buenos Aires (del cual lo ocurrido en la ciudad de Necochea es expresión) y el aumento de la precarización de la fuerza de trabajo (Mateo, Nieto y Colombo, 2010). En segundo lugar, aconteció luego de la oleada masiva de recuperaciones de empresas, en una ciudad cuya tradición en este tipo de experiencias era escasa y desconocida para los obreros de Industrial Pesquera. ${ }^{2}$ En tercer lugar, es peculiar la efectividad de ciertas acciones directas de los obreros, que lograron imponerse sobre la voluntad patronal de cerrar la fábrica y efectuar los despidos sin mediar conflicto.

Del total de los 27 trabajadores con relación contractual por tiempo indeterminado que alli se desempeñaban, fue una minoría de 7 obreros

2. De acuerdo a nuestros rastreos sobre la historia local de las empresas recuperadas en Necochea, hasta el momento hemos hallado una primera experiencia de corta vida entre los años 1999 y 2000, en la panadería llamada "La Central". La cesión de los bienes inmuebles y maquinarias se realizó de forma pacífica por un mutuo acuerdo entre el empresario y los trabajadores. Luego, en el año 2003 se conformó como empresa recuperada la cooperativa de salud "Libra", que funcionaba en la ciudad como sociedad anónima desde el año 1979, y también se caracterizó por la transición pacífica a la figura de cooperativa. 
la que dio los primeros pasos y finalmente llevó a cabo la recuperación de la empresa, entre los meses de enero y abril del año 2011. A ese grupo original se sumó un trabajador temporario que había sido peón en la planta años anteriores, y un miembro de una organización de la llamada "izquierda popular", Frente Popular Dario Santillán (FPDS), ${ }^{3}$ que participó activamente del proceso de recuperación.

El nombre que eligieron para la cooperativa de trabajo enmarcada en el proyecto autogestivo fue "La Recuperada", cuya conformación inicial fue de nueve integrantes. De acuerdo a su género, tarea y tipo de relación contractual, vemos que siete eran varones y dos mujeres, de los cuales ocho tenían una vinculación con la firma anterior, dos eran fileteros, cuatro eran peones y dos envasadoras; cuatro poseían contrato por tiempo indeterminado, tres eran eventuales y uno temporario (que al momento de la recuperación realizaba la venta ambulante de pescado fresco). El miembro de la organización del FPDS se encontraba desocupado cuando se integró a la cooperativa, y cursaba el segundo año de las carreras Licenciatura en Administración de Empresas y Contabilidad. En la siguiente tabla volcamos la información precedente, a la cual se agregan los nombres y los cargos que ocuparon cada uno de los integrantes en el consejo de administración de la cooperativa conformada:

Tabla 1. Conformación inicial del colectivo obrero de La Recuperada

\begin{tabular}{|l|l|l|l|}
\hline Nombre & Puesto anterior & Tipo de contratación & Cargo en cooperativa \\
\hline Darío & Filetero & Planta permanente & Presidente \\
\hline Julio & Peón & Planta permanente & Secretario \\
\hline Mario & Filetero & Planta permanente & Síndico \\
\hline Hugo & Peón & Eventual & Tesorero \\
\hline Angélica & Envasadora & Planta permanente & Vocal \\
\hline Natalia & Envasadora & Eventual & Vocal \\
\hline Edgardo & Peón & Eventual & Vocal \\
\hline Julián & Peón & Temporario & Vocal \\
\hline Matías & Desocupado & - & Vocal \\
\hline
\end{tabular}

Fuente: Elaboración propia en base a las entrevistas realizadas.

3. Esta organización, a nivel nacional, nació a partir del movimiento de desocupados organizado en el marco de la crisis neoliberal de 2001. Fue un desprendimiento del MTD Aníbal Verón, y sus posicionamientos políticos incluyen la coexistencia de variadas tradiciones de izquierda, autonomistas y peronistas. En el caso de Necochea, quienes fueron sus fundadores y participaron activamente en este proceso de recuperación eran adherentes del movimiento zapatista. Desde esa perspectiva pregonaban la autogestión y la autonomía con respecto al patrón capitalista. 
Como sucede en la mayoría de este tipo de emprendimientos obreros, conformaron cooperativas de trabajo a fin de poder gestionar subsidios, el ingreso a programas estatales y también guardar el carácter jurídico necesario para solicitar los permisos provisorios para la continuidad laboral inmediata y la expropiación de la unidad productiva (Brunet y Pizzi, 2011: 269). En los meses iniciales del conflicto contaron con un importante apoyo social, político y comunitario, ya que intervinieron a favor de los trabajadores la dirigencia local del Sindicato de Trabajadores de la Industria Alimenticia que los nucleaba, la organización Cruz del Sur que formaba parte del Frente Popular Darío Santillán, docentes y estudiantes de la carrera terciaria de Trabajo Social, investigadores, la Corriente Sindical Peronista (CSP, agrupación liderada por Hugo Moyano a nivel nacional) que integraba la CGT, funcionarios y concejales del kirchnerismo y el peronismo federal, y vecinos.

El caso se produjo durante el gobierno nacional de Cristina Kirchner, en una etapa que Dinersteinubica como marcada por la contención estatal de este tipo de experiencias (2007: 544). De acuerdo a la autora, esta política se inició a partir del año 2003 con el objetivo de "despolitizar" las acciones más radicales de los trabajadores (2007: 529), lo cual se expresa en los programas sociales destinados a este tipo de experiencias desde el Ministerio de Trabajo, Empleo y Seguridad Social (tales como el Programa de Trabajo Autogestionado, que llegó a incluir a 318 empresas recuperadas hacia 2013) $)^{4}$ y en las facilidades estatales otorgadas para realizar la inscripción como cooperativa con la mediación del Instituto Nacional de Asociativismo y Economía Social. En el ámbito local gobernaba el radicalismo, y la principal fuerza política opositora era el kirchnerismo, apoyado por la CSP. Esta corriente política y sindical se presentaba como opositora a otro sector de la CGT vinculado al espacio politico denominado 62 Organizaciones Gremiales Peronistas, conducido por el "Momo" Venegas. ${ }^{5}$ La CSP, en comunicados de prensa referidos a la situación en la fábrica pesquera, expuso a su vez críticas al ejecutivo y otros reclamos municipales, ${ }^{6}$ y luego impulsó la candidatura electoral de Horacio Tellechea, concejal en funciones al momento del cierre de Industrial Pesquera, que resultó ganador de la intendencia en octubre de 2011.

4. "Informe del Programa de Trabajo Autogestionado", del Ministerio de Trabajo, Empleo y Seguridad Social de la Nación, noviembre de 2013.

5. Un desarrollo del posicionamiento político de la CSP hacia fines del año 2010 puede encontrarse en el diario digital Voces de Necochea, en un artículo publicado el 13 de noviembre de 2010, disponible en www.vocesdenecochea.com.ar/noticias/ print.php?id $=1289665680$ \&archive $=1297547489$

6. Ecos Diarios, 31 de enero y 25 de abril de 2011. 
La seccional necochense del STIA estaba dirigida por Juan Pablo Moreno (de filiación política peronista) y alineada -durante el tiempo en el que se desarrolló el conflicto- con la CSP. Su accionar fue diferente en los tres cierres empresariales ocurridos en la zona entre 2011 y 2012: Industrial Pesquera, Engraucoop y Incoop. Si bien en diversas ocasiones acompañó e impulsó acciones junto a los obreros para impedir el cierre de las fábricas y participó de las reuniones en el Ministerio de Trabajo hasta el ingreso al concurso de acreedores, solo en el caso de La Recuperada promovió la recuperación de la empresa y la conformación de la cooperativa. En el caso de Engraucoop, se desvinculó del colectivo obrero una vez que la patronal se retiró de la fábrica, y las obreras llevaron a cabo la conformación de la cooperativa de trabajo con el asesoramiento de funcionarios de la Secretaría de Producción y empleados del Instituto Nacional de Asociativismo y Economía Social (Nogueira, 2013: 4-5). En el caso de Incoop, la dirigencia gremial fue parte del acuerdo con el empresariado que pautó el compromiso del pago de las indemnizaciones a la totalidad de empleados al momento de la quiebra. ${ }^{7}$ Esta diferenciación en su política ante los tres cierres de empresas pesqueras locales muestra que la promoción de la recuperación con autogestión obrera no formaba parte de su lineamiento político. De acuerdo a testimonios obreros, en febrero comenzaron a realizarse asambleas abiertas en la fábrica con frecuencia semanal en las que se debatía sobre posibles acciones a realizar, a las que además de los trabajadores de Industrial Pesquera concurrian asiduamente el secretario gremial y el abogado del STIA, integrantes de la organización del FPDS y docentes y estudiantes de la carrera de Trabajo Social del ISFD n ${ }^{\circ} 31$. En ese contexto, en el mes de marzo de 2011 comenzó a circular la posibilidad de conformar una cooperativa de trabajo y de recuperar la empresa, idea que los obreros atribuyeron al FPDS y al STIA. La transmisión de las experiencias de la fábrica ceramista Zanón ${ }^{8}$ y del Hotel Bauen ${ }^{9}$ actuaron como puentes para que los trabajadores conozcan en términos concretos de qué se trataba esta propuesta. Así lo expresan dos testimonios:

\section{Ecos Diarios, 1 de febrero de 2012.}

8. La experiencia de Zanón fue transmitida a los obreros por parte de integrantes del FPDS a través de un audiovisual realizado por los trabajadores de la fábrica ceramista. Luego, este video fue expuesto en una de las peñas realizadas en la planta de Industrial Pesquera, en el marco del conflicto.

9. La experiencia del Hotel Bauen fue transmitida por miembros del equipo de investigación dirigido por el doctor José Mateo, que junto a él se acercaron a brindar apoyo a la fábrica durante el conflicto. 
Nos empezamos a informar, ahí vino Santiago [dirigente del FPDS], vino con sus ideas, sus cosas, nos empezó a explicar junto con Guille [abogado del STIA] cómo era el tema de la cooperativa. Nosotros teníamos ganas de trabajar, no sabíamos qué nombre ponerle, cooperativa o no cooperativa, no sé qué formato. La idea era ponernos a laburar. (Dario, trabajador de La Recuperada, 35 años) ${ }^{10}$

...del video de Zanón, creo que de ahí salió todo y nos dio un poco más de fuerza, o sea, de fuerza de todo lo que podíamos hacer, yo cuando entre acá no tenía ni idea que me podía quedar acá y trabajando de forma de trabajador, trabajando entre nosotros. (Julián, trabajador de La Recuperada, 29 años) ${ }^{11}$

Cabe destacar que, previamente al conflicto por la recuperación, no habia vínculos previos entre el FPDS y obreros de Industrial Pesquera, y que la decisión de concurrir a la planta por parte de integrantes de Cruz del Sur fue motivada a partir del conocimiento del conflicto mediante la prensa local.

A continuación, presentaremos una breve crónica de este proceso de lucha obrera, a la que luego añadiremos referencias a conflictos previos y sus vínculos con la recuperación. Su reconstrucción fue efectuada a partir de un encuadre metodológico que incluyó una pluralidad de fuentes y técnicas de recolección de datos. Por un lado, fuentes orales que se basaron en entrevistas semiestructuradas individuales y grupales realizadas entre los años 2011 y 2018. En las mismas participaron trabajadores, miembros de la dirigencia sindical y de la organización del FPDS. Asimismo, efectuamos observaciones no participantes en la fábrica durante el curso del conflicto y posteriormente a la conformación de la cooperativa. Por otra parte, mediante la observación y análisis documental abordamos fuentes escritas, que consistieron en archivos de la prensa gráfica local, de la empresa recuperada, judiciales, documentos oficiales del Instituto Nacional de Investigación y Desarrollo Pesquero, el Ministerio de Agricultura, Ganadería y Pesca, la Secretaría de Pesca y Acuicultura de la Nación, y literatura académica sobre el sector pesquero nacional. También utilizamos fuentes audiovisuales que incluyeron documentales realizados por los propios obreros y medios de comunicación locales.

10. Entrevista grupal a La Recuperada, realizada por la autora el 24 de octubre de 2011. Las edades de los entrevistados corresponden al momento de realización de las entrevistas.

11. Entrevista a Julián, realizada por la autora el 30 de octubre de 2011. 


\section{Crónica del conflicto por la recuperación}

El conflicto en Industrial Pesquera S.A. se inició en diciembre de 2010 a raíz de la parálisis de la producción, cese del pago de los salarios y desabastecimiento de materia prima. Los propietarios de la firma eran Concepción Ursino y sus dos hijos, Pablo Bruno y Carmelo Bruno, que se dividian las acciones en partes iguales desde su instalación en la ciudad en el año 1972 hasta el momento del ingreso al concurso de acreedores como antesala de la quiebra. En el marco de la inactividad en la planta, los empresarios ofrecieron a los trabajadores tomarse una licencia sin goce de sueldo. La mayoría de los trabajadores no aceptó, ya que significaba pasar varios dias sin ingresos, en fechas que incluian los festejos de fin de año. Por eso, decidieron continuar yendo a la planta procesadora ubicada en la zona portuaria local a cumplir horario con la ropa de trabajo. Las jornadas se aletargaban ya que no habia tareas que realizar, por lo que transcurrian entre charlas y mates en la cocina de la planta. Estas acciones no eran habituales en la cotidianidad obrera fabril, en la cual solo se disponía de quince minutos de descanso por jornada laboral en forma separada para fileteros, peones y envasadoras. Luego de varios días, al no obtener respuestas por parte de la patronal, un grupo de obreros planteó salir a la vereda de la planta y quemar gomas en la calle aledaña, para visibilizar que estaban sin trabajo y sin ingresos. Darío y Rubén, delegados gremiales de planta, interpelaban todos los días a los empresarios para exigirles el pago de los salarios atrasados, sin obtener respuesta. La bronca se incrementaba día a día, y tuvo un punto de inflexión cuando un trabajador encontró a la propietaria de la empresa en un hipermercado local, con su carro de compras lleno de productos. La noticia se esparció con indignación entre los obreros y motivó que, tras una insistencia telefónica de Darío, los empresarios concurrieran a la planta con 2.200 pesos para distribuir entre todos los trabajadores que alli se encontraban. Su reparto dio un total de 120 pesos para cada uno, lo cual representaba entre el 4 y el $5 \%$ de su salario promedio para el año 2010.

En ese momento, un trabajador (Julio), expresó a Darío la idea de utilizar ese dinero para comprar pescado en la banquina del puerto, procesarlo y luego venderlo. Darío estuvo de acuerdo con la propuesta, ambos la compartieron con el resto de los trabajadores y consiguieron que otros dos se unieran a ese proyecto autogestivo. Un quinto obrero fue el encargado de realizar la compra de pescado en la banquina, ya que era quien efectuaba esta tarea en Industrial Pesquera y por ello tenía vínculos previos con los capitanes de barco que allí desembarcaban. Filetearon el pescado entre los cuatro, pero solo Darío y Julio salieron a venderlo de forma ambulante. Una vez terminada la venta de la totalidad 
de pescado procesado, los integrantes del grupo autogestivo lograron duplicar los 120 pesos iniciales. En las semanas siguientes repitieron el procedimiento cada vez que obtuvieron pescado en el puerto.

La situación conflictiva en la fábrica cobró un nuevo viraje a inicios de febrero, cuando al llegar los trabajadores se encontraron con la planta cerrada sin la presencia de la patronal. Darío fue el encargado de consultar qué sucedía al sereno de la fábrica de hielo lindante, empresa cuyos propietarios eran los mismos dueños de Industrial Pesquera. Este empleado refirió que tenía la llave de la planta, pero también órdenes patronales de no abrir la puerta. A los pocos minutos ya circulaba entre los obreros la idea de entrar a la planta y ocuparla, para que los empresarios no vuelvan a impedir el ingreso. A tal fin, un grupo fue a buscar gomas por el barrio para cortar la calle nuevamente. Uno de los propietarios acudió prontamente a la planta, y tras una discusión le dejó la llave a Darío.

A partir de allí comenzó la ocupación permanente de la fábrica. Además de Darío y Julio, otros obreros se sumaron a pasar la noche. Uno de ellos fue Julián, que había sido trabajador temporario en la planta y pasó una mañana de enero vendiendo cornalitos. Allí se anotició del conflicto y comenzó a participar activamente de las acciones emprendidas.

En esas semanas iniciales se acercaron a los obreros las organizaciones políticas y actores comunitarios mencionados en el apartado anterior. Se realizaron varias audiencias en la sede local del Ministerio de Trabajo, a las que concurrian representantes empresariales y gremiales. Los empresarios aducian una crisis por la cual habian contraído grandes deudas que no podian pagar con proveedores y entidades públicas, debido a un descenso de la rentabilidad. Por esta misma razón, decían, tampoco poseían dinero para abonar los sueldos atrasados. Entonces, como resultado de estas primeras reuniones en la dependencia estatal, se procedió a solicitar ayuda financiera tanto al gobierno nacional como provincial, con intermediación de funcionarios y concejales locales ligados al kirchnerismo. En sus inicios, las gestiones realizadas fueron en vistas al ingreso al programa REPRO, destinado a empresas en crisis, y a los créditos Bicentenario, lanzados desde el año 2010. ${ }^{12}$ Sin embargo, con el correr de los días quedó en evidencia la distancia entre los montos que ofrecian los planes de financiamiento estatal y la suma que según los propietarios era necesaria para reactivar la fábrica..$^{13} \mathrm{El}$ retiro definitivo de la patronal se concretó a principios de abril. ${ }^{14}$ En este nuevo contexto la conformación de una cooperativa de trabajo se presentó

12. Ecos Diarios, 8 de febrero de 2011.

13. Ecos Diarios, 31 de marzo de 2011.

14. Ecos Diarios, 7 de abril de 2011. 
como la única posibilidad de continuidad laboral. Fue entonces cuando el emprendimiento espontáneo de fileteado de pescado en la planta se enlazó con un movimiento más amplio a nivel nacional e internacional: la recuperación de empresas con autogestión obrera de la producción.

En el transcurso de estos cuatro meses, muchos obreros se retiraron de la fábrica impulsados por la necesidad de obtener otro trabajo en vistas de la reproducción propia y de su familia. ${ }^{15} \mathrm{El}$ tiempo extendido durante el cual no obtuvieron ningún ingreso (a excepción de los 120 pesos anteriormente mencionados) fue uno de los factores que contrariaron el involucramiento de la totalidad de obreros en la recuperación, cuestión que algunos de los integrantes de La Recuperada combatieron con la venta ambulante de pescado durante enero, febrero y marzo. Las amenazas patronales, que versaban sobre la imposibilidad de obtener financiamiento estatal para lograr la reactivación de la unidad productiva si se conformaba una cooperativa, fue otro punto que jugó en contra de la decisión de un sector de obreros para integrar el formato laboral autogestivo. Además de una aversión hacia la forma "cooperativa", ${ }^{16}$ vinculada con las propias experiencias en cooperativas fraudulentas. ${ }^{17}$ Finalmente, el descreimiento de que los obreros, por sí solos, podrian llevar adelante una fábrica ${ }^{18}$ también operó como limitante para la integración al formato autogestivo. A pesar de todo esto, la recuperación fue emprendida por un tercio de los trabajadores de planta de Industrial Pesquera, que vencieron todos estos obstáculos.

El grupo autogestivo, a excepción de Darío y Julio, fue fluctuante en cuanto a sus miembros durante sus primeros dias. Finalmente, se incorporaron los 6 trabajadores que junto a ellos conformaron "La Recuperada", constituida como cooperativa de trabajo entre fines de abril y principio de mayo del 2011. Debido a que en algunas oportunidades tenian dificultades para adquirir materia prima en el puerto, buscaban otras tareas laborales que les permitieran obtener algún ingreso, tales como lavado de autos en la planta, venta de hielo y organización de peñas.

A continuación, realizaremos un análisis de las luchas previas tenien-

15. Ecos Diarios, 31 de marzo de 2011.

16. Entrevista a Mario, 52 años, filetero en La Recuperada, realizada por la autora el 27 de octubre de 2011.

17. En referencia a las cooperativas conformadas por el empresariado a fin de precarizar la fuerza de trabajo en la industria pesquera, formato laboral que se impuso en los 90 en el sector pesquero bonaerense en el marco de la crisis y reconfiguración de la industria pesquera (Mateo, Nieto y Colombo, 2010)

18. Entrevista a Julián, realizada por la autora el 30 de octubre de 2011. 
do en cuenta sus objetivos, sus resultados y su impacto en el proceso de recuperación posterior.

\section{Las luchas previas como detonantes de combates futuros: recuperando la potencia de la clase obrera}

Cuando la industria prospera, los patronos obtienen grandes beneficios y no piensan en compartirlos con los obreros; pero durante las crisis tratan de cargar las pérdidas sobre los obreros.

Lenin (2013: 6)

Lenin, en su texto "Sobre las huelgas", expresa que las mismas surgen de la necesidad de los obreros de luchar colectivamente contra los patrones por sus reivindicaciones, ya que, individualmente, el obrero es impotente frente al patrón (2013: 5). Les atribuye a las huelgas varias funciones. En primer lugar, durante las mismas los trabajadores reconocen y se rebelan ante las condiciones de explotación que habian soportado en "tiempos pacíficos", y exigen la modificación de las mismas (Lenin, 2013: 7). En segundo lugar, generan unidad de la clase permitiendo que los obreros se reconozcan como iguales e identifiquen al capitalista como su enemigo. En tercer lugar, pueden producir adhesión y apoyo social, por parte de otras fábricas de la rama y de las ubicadas en sectores aledaños. Finalmente, les adjudica una poderosa influencia moral al cuestionar la desigualdad de clases, porque los obreros pasan de considerarse "esclavos" a "personas con los mismos derechos que los ricos" (Lenin, 2013: 8). Por todo ello, y por su potencial para conducir -con la mediación de la propaganda revolucionaria- a la conclusión de la lucha socialista, Lenin las considera "escuelas de guerra" (Lenin, 2013: 11). Este concepto lo retoma de Engels, quien se refirió de igual manera a las huelgas en La situación de la clase obrera en Inglaterra, en donde resalta la valentía obrera que permiten desplegar y la eficacia sin igual en el combate contra la dominación de la burguesía (Engels, 1974: 316). Aquí nos parece interesante retomar este concepto, imbricado con el de "potencial clasista" previamente mencionado, extendiendo a todo formato de lucha obrera esta posibilidad de constituirse como "escuela de guerra". Siguiendo a Collado y Roitman, retomamos el papel de los conflictos previos en cuanto a su incidencia en la historia y la memoria de los grupos obreros que los emprenden, ya que "permiten anudar la historia y la trayectoria con el presente, tanto de las configuraciones socioespaciales y económicas como de las tradiciones de lucha y enfrentamientos" (2015: 171). A su vez, sus lecciones permiten retomar 
prácticas conjuntas de organización y lucha contra el capital, ya que la propia práctica permite aprender sobre "la organización colectiva y la configuración de una praxis de clase" (2015: 151).

En primer lugar, hallamos referencias obreras sobre acciones conflictivas previas que iniciaban en el año 2005 y se remitian a las condiciones de trabajo al interior de la planta de Industrial Pesquera, vinculadas con determinados formatos de explotación capitalista en el proceso de trabajo mediante diversos mecanismos que burlaban la legislación laboral vigente:

Dario: Arrancamos con los reclamos y medidas para mejorar las condiciones laborales de los trabajadores: pago de horas extras, entrega de ropa de trabajo, se consiguió que nos den los tiempos de descanso según la ley de contrato de trabajo, que nos paguen en tiempo y forma, se efectivizó a personas que estaban pasadas en tiempo de contrato eventual, se dejó de utilizar mujeres para trabajar dentro de la cámara de frío, como así también se eliminó la tarea de trabajo pesado a mujeres.

Entrevistadora: ¿Qué medidas tomaron para obtener esos reclamos?

Dario: Nunca fue necesaria una medida de paro total de la planta, fue un trabajo de presión en conjunto entre el sindicato, la comisión interna y los compañeros para lograr las mejoras laborales que necesitábamos. Hacíamos reuniones y cuando no cumplían parábamos de trabajar. Ellos nos respetaban mucho porque nosotros siempre íbamos en apoyo cuando había conflicto en otras fábricas, y sabían que si llegamos a tener que tomar una medida de fuerza grande íbamos a contar con mucho apoyo y no querian tener un quilombo grande. (Dario, 42 años, filetero de La Recuperada) ${ }^{19}$

Los combates precedentes se referian a la recuperación de ciertas condiciones de trabajo que fueron arrebatadas mediante la flexibilización y precarización laboral que en el sector pesquero se implementaron con fuerza en la década del 90 , en un contexto de cierres empresariales, incremento de la concentración del capital en las grandes corporaciones pesqueras y cooperativización fraudulenta de gran parte de la fuerza de trabajo (Mateo, Nieto y Colombo, 2010), que para 1996 alcanzaba a $40 \%$ de la fuerza de trabajo en el sector industrial pesquero de la provincia de Buenos Aires (Bertolotti, Erratzi y Pagani, 1997). A pesar de la recuperación y crecimiento posterior a 2003, el empresariado mantuvo

19. Entrevista a Darío, filetero y delegado de Industrial pesquera, realizada el 2 de marzo de 2018. 
intactos estos niveles de precarización laboral, y para revertirlos fue necesario recurrir a la lucha obrera. En las entrevistas, Darío menciona que tras su elección como delegado comenzó a entablar vínculos con la dirigencia gremial local, y a cotejar junto a sus compañeros diferencias entre sus condiciones de trabajo reales con respecto a las pautadas por el Convenio Colectivo de Trabajo $\mathrm{n}^{\circ} 372 / 04$, que regula la contratación laboral y las remuneraciones en la rama para la ciudad de Necochea. La identificación de estos incumplimientos fue resultado de la vivencia material diaria en la fábrica como peones, ya que para este puesto de trabajo no se cumplian reglamentaciones que sí se respetaban para el caso de los fileteros. Los obreros observaron, con el convenio en mano, que este incumplimiento era una imposición de la patronal de la fábrica, ya que la letra del convenio pautaba similares derechos laborales para peones y fileteros. A su vez, de la lectura de la reglamentación también se deducía la carencia de otros derechos que afectaban a todos los puestos de trabajo.

Cotejando los reclamos obreros con el CCT n ${ }^{\circ} 372 / 04$, podemos situar diferentes mecanismos de incremento de la explotación "legal" que implementaba la patronal, haciendo caso omiso a las regulaciones planteadas por dicho convenio:

- el incumplimiento del pago de los salarios y horas extras en la fecha estipulada;

- la contratación por tiempo indeterminado de peones eventuales que ya habian finalizado el tiempo máximo estipulado bajo el tipo de contratación en forma temporal;

- el incumplimiento de la provisión de ropa y herramientas de trabajo;

- el retraso en el inicio de los tiempos de descanso, que se aplicaban una hora después de lo estipulado, eran más cortos con respecto a lo establecido por ley y a su vez se aplicaban en distintos horarios para los fileteros y para los peones, y

- la imposición de tareas que excedian las propias del puesto de trabajo para las mujeres, tales como tareas pesadas o en la cámara de frío. ${ }^{20}$

Por todos estos motivos, los obreros de Industrial Pesquera realizaron acciones diversas, como reuniones, huelga de brazos caídos, manifestaciones en el interior de la planta procesadora; y lograron eliminar

20. Ver el Convenio Colectivo de Trabajo n ${ }^{\circ}$ 372/04: contratación de personal eventual y plazos para la contratación por tiempo indeterminado (arts. 7 y 9), fecha de pago de los salarios (art. 21), pago de horas extras (art. 64), turnos de descanso (art. 61), equipo de trabajo (art. 65) y exclusión de las mujeres del trabajo pesado e insalubre (arts. 70 y 71 ). 
uno a uno estos mecanismos de precarización laboral, a excepción de la contratación por tiempo indeterminado de trabajadores eventuales, que se obtuvo solo en algunos casos.

Primeramente, el reclamo se efectuó de manera individual por parte del delegado de planta, quien concurrió en varias oportunidades a las oficinas de la patronal y expuso las reivindicaciones obreras. El resultado fue infructuoso, los patrones o bien no atendian a Darío, o bien contestaban que tales solicitudes "no correspondian". Fue entonces que los obreros decidieron implementar medidas conjuntas afectando la producción en la planta, y tras obtener sus primeros objetivos se convencieron de que esa era la forma por la cual podian imponerse sobre la patronal.

Las vivencias previas de unidad y solidaridad interfabril en la industria pesquera local se remontaban al año 2004, cuando parte de la fuerza de trabajo de Industrial Pesquera se desempeñaba en una cooperativa fraudulenta integrada por fileteros y peones de diferentes fábricas. Tras meses de soportar una extendida precarización laboral y bajas remuneraciones, decidieron unirse y plantear la exigencia del régimen de contratación como asalariados. Para ello efectuaron una acción judicial que consistió en la renuncia de la totalidad de integrantes de la cooperativa y una gran manifestación en el Ministerio de Trabajo, que tuvo el apoyo de obreros que ya eran efectivos en las distintas plantas pesqueras. Finalmente, la cooperativa fue disuelta y sus trabajadores fueron incorporados como asalariados efectivos, dejando como saldo sedimentos de solidaridad interfabril disponibles para futuros conflictos. Otra consecuencia de este conflicto fue la constitución del liderazgo de Darío, constatada en su elección como delegado de planta tras quedar efectivo en Industrial Pesquera. Hasta ese momento, Darío no tenía vínculos con la dirigencia sindical ni con corrientes políticas dentro o fuera del gremio, y solo tras su elección concurrió a la sede local del STIA a informarse sobre legislación laboral y plantear denuncias sobre condiciones de trabajo intrafabriles.

Retomando los avatares de la lucha por la recuperación en su período inicial, al rechazar la propuesta de vacaciones impagas y continuar concurriendo a la fábrica, esas jornadas laborales sin actividades a realizar posibilitaron la vivencia de un tiempo compartido entre los trabajadores. El tiempo y espacio fabril se reconfiguró y permitió la preparación de la lucha contra los despidos y cierre de la empresa. Así lo expresan testimonios de obreros:

Hasta que llegó el momento de salir a la calle. "Vamos a salir afuera, estamos acá cagándonos de calor..." Estábamos acá adentro y nadie nos veía lo que nos pasaba a nosotros, 
nadie sabía. Hasta que un día empiezan a surgir algunas ideas, por qué no empezamos a quemar gomas, empezamos a hacer esto, a hacer lo otro... Y bueno yo siempre lo que me pasó en ese momento era decirle a los compañeros que a mí me ha tocado tener experiencia de otros conflictos al ser delegado, de compartir conflictos en otras fábricas y he tenido un poco más de experiencia en eso. Un conflicto arranca y sabés cuándo empieza pero no sabés cuando termina, y cuando uno está decidido tiene que estar muy decididos y concientes aunque a veces la necesidad y todo te impulsa a decir acá hay que hacer algo, hay que salir, hay que salir. Pero yo lo que volcaba en mis compañeros era que se arranca y hay que seguir y no hay que abandonar y acá va a haber desgaste... (Darío, 35 años, filetero de La Recuperada) ${ }^{21}$

Esta reconfiguración contrarió las intenciones de la patronal, que buscaba realizar el vaciamiento de la empresa y llegar al inicio del concurso de acreedores como antesala de la quiebra con la fábrica vacía, y su fuerza de trabajo ya desarticulada e individualizada, resignada a su destino de desempleo.

En este período previo a la toma de la planta las acciones directas fueron emprendidas por los propios obreros, y en algunas de ellas tuvieron el acompañamiento de la dirigencia gremial y del FPDS. La CSP expresó su apoyo de forma indirecta, mediante una declaración en la prensa en la que manifestó "solidaridad con los trabajadores de Industrial Pesquera". 22

¿Por qué consideramos que las luchas previas influyeron en el conflicto por la recuperación? En primer lugar, porque generaron cierta experiencia compartida que hizo palpable la efectividad del reclamo colectivo, y otorgaron determinados saberes sobre la posibilidad de imponer los objetivos obreros relativos a la continuidad laboral en el contexto inicial del conflicto.

En segundo lugar, promovieron la constitución de ciertos liderazgos que luego se volcaron en el proceso de recuperación, en especial en la figura del delegado gremial, pero extendida a todo el grupo que junto a él emprendió las diversas acciones de combate, que se autodenominaban como "los que estábamos más firmes al lado de Dario". ${ }^{23}$ Como ejemplo de actualización de un aprendizaje producto de luchas previas,

21. Entrevista grupal a La Recuperada, realizada por la autora el 24 de octubre de 2011.

22. Ecos Diarios, 30 de enero de 2011.

23. Entrevista grupal a La Recuperada, realizada por la autora el 24 de octubre de 2011. 
observamos que Darío pudo anticipar el desgaste que el conflicto podría provocar, que se expresó en su extensa duración.

En tercer lugar, el grupo de obreros que encabezó las diversas acciones emprendidas obtuvo el apoyo de trabajadoras y trabajadores de la fábrica pesquera Engraulis, con la cual ya habia experiencias previas de lucha compartida. Este apoyo se materializó en la presencia de esos obreros en la planta: "La gente de Engraulis nos venía a acompañar acá a tomar mate, traían ellos torta", y también en el aporte de insumos para la realización de las peñas: "Las compañeras de Engraulis deciden donarnos 5 kilos de carne y hacerlos el sábado". ${ }^{24}$

En cuarto lugar, vemos que la obtención de sucesivas conquistas de derechos fabriles producto de las luchas previas generó lo que Lenin describe como "poderosa influencia moral", en el sentido de que los obreros llegaron a la conclusión de que para obtener sus derechos negados debían alzarse contra la patronal. Esta influencia no se detuvo al concluir el conflicto con la salida autogestiva, sino que se extendió luego de haberse consumado la recuperación de la fábrica, como veremos a continuación.

\section{La recuperación de la empresa y las nuevas conquistas sobre la base de las luchas previas}

Eso es lo que tienen los patrones, te hacen socio cuando van en pérdida o no ganan lo que tienen que ganar. Ahora, cuando ganan mucho no te hacen socio, de compartir las ganancias o darte más plata cuando hubo una buena exportación.

Dario, trabajador de La Recuperada, 35 años

El carácter de las luchas parciales previas como "escuelas de guerra" también se manifestó en los momentos inmediatamente posteriores al conflicto a partir de abril de 2011, cuando se conformó la cooperativa "La Recuperada", en tres puntos principales.

Por un lado, en el cuestionamiento de la división obrera que la patronal impuso en la planta entre fileteros, peones y envasadoras, que generó mayor unidad en el grupo autogestivo.

Por otra parte, en el cuestionamiento de la obligación de tareas pesadas a las mujeres, que se impuso ubicando el cuidado del cuerpo

24. Entrevista grupal a La Recuperada, realizada por la autora el 24 de octubre de 2011. La participación de trabajadores de Engraucoop en el proceso también se constata en La Recuperada: una historia de lucha, trabajo y dignidad, documental realizado por integrantes de la Cooperativa Coomuniccar, del año 2011. 
femenino obrero por encima de la repartición de tareas. Finalmente, en el cuestionamiento hacia el empresariado, que generó un acrecentamiento en la concientización sobre el carácter desigual de la relación capital-trabajo.

En referencia a la división entre fileteros y peones, la rebelión contra el trato distintivo en cuanto a derechos laborales formó parte de las luchas previas, y se expresó en las entrevistas mediante diversas frases:

Estaba muy dividido en el trabajo lo que eran los fileteros y los peones. El operario por hora ganaba una plata y el filetero otra, había una diferencia abismal entre lo que cobrara uno y el otro, y diferencia no solamente en plata sino también en los beneficios. (Darío, 35 años, filetero de La Recuperada) ${ }^{25}$

Los peones y las envasadoras trabajaban al margen de los fileteros, es por un tema que yo creo que es que yo gano tanto y soy más que vos, porque nosotros ganábamos mucho menos de la mitad que ganaba un filetero, si el filetero ganaba doscientos pesos nosotros ganábamos sesenta, y en relación trabaja más el peón que el filetero, es más fuerte el trabajo, y además que de las puertas para afuera somos todos iguales. (Julián, 29 años, filetero de la Recuperada) ${ }^{26}$

En estas narrativas obreras observamos una tensión relativa a la división que la patronal buscó imponer entre los trabajadores, al oponer puestos de trabajo no solo en cuanto a su función sino en cuanto a derechos laborales, tiempos de trabajo y salarios. Por ello, vemos que el reclamo se refería no tanto a las tareas sino al mayor grado de precarización impuesto por el empresariado hacia peones y envasadoras.

El CCT, como acuerdo entre las partes (sindicato y patronales), contiene las fórmulas para el cálculo salarial estipulado para los tres puestos de trabajo que, como vemos en la tabla $\mathrm{n}^{\circ} 2$, muestra diferencias significativas. ${ }^{27}$

25. Entrevista grupal a La Recuperada, realizada por la autora el 24 de octubre de 2011.

26. Entrevista a Julián, realizada por la autora el 30 de octubre de 2011.

27. Para realizar un cálculo comparativo de los salarios de los diferentes puestos de trabajo tomaremos como base el CCT $n^{\circ} 372 / 04$, que establece un pago por hora de $\$ 3$ para peones y envasadoras y un pago promedio por kilo de $\$ 0,25$ para los fileteros, y tomaremos como referencia para las tres categorias de trabajadores una jornada laboral de 8 horas diarias de lunes a sábados, un total mensual de 200 horas de trabajo total, y para los fileteros, un promedio mensual de 3.750 kilos fileteados por mes (extraído de Zelaya, 2013). 
Tabla 2. Estimación de salarios básicos mensuales correspondientes a las categorías de peones, envasadoras y fileteros para el año 2010

\begin{tabular}{|l|c|c|}
\hline Puesto de trabajo & Cálculo salarial & Salario básico mensual \\
\hline Peones y envasadoras & $\$ 10,74 \times 200$ horas & $\$ 2.148$ \\
\hline Fileteros & $\$ 0,82 \times 3.750$ kilos & $\$ 3.075$ \\
\hline
\end{tabular}

Fuente: Elaborado en base a la Disposición n² 287/2010 del Convenio Colectivo de Trabajo n 372/04.

De acuerdo a los testimonios, la diferencia era aún mayor que la expresada en la tabla, pero tomando el cálculo salarial basado en el CCT, se estima para los fileteros un salario superior al menos ${ }^{28}$ en un $50 \%$ en relación con el de los peones y las envasadoras, para una misma jornada laboral. Sin embargo, en Industrial Pesquera la división entre fileteros, peones y envasadoras no se limitaba a las condiciones de trabajo previstas en la legislación (referidas a las tareas a desempeñar y el cálculo salarial), sino que los propietarios añadian otros dispositivos para provocar una mayor división: la obligación de cumplir horas extras para los peones (a riesgo de quedar desempleado de no cumplirlas) y la imposición de tareas pesadas y en cámaras de frío para las mujeres.

Al adjudicarles tareas propias del puesto de peón a las mujeres envasadoras, el empresariado incrementaba su explotación sobre la fuerza de trabajo femenina y generaba una nueva división intraobrera. También se ahorraba la contratación de nueva fuerza de trabajo para ejecutar estas tareas, reduciendo el número de peones necesarios para efectuar las labores en la planta.

En contraposición con esta división, que expresaba una jerarquía intraobrera al interior de la planta, los integrantes de La Recuperada decidieron eliminar las categorias laborales y abordar la totalidad de tareas de la producción en forma conjunta: todos realizaban la carga, descarga, fileteado y envasado del pescado, a excepción de las mujeres, para quienes mantuvieron la conquista previa de la eliminación de las tareas pesadas. Además, decidieron efectuar una repartición igualitaria de los ingresos, replicando el mecanismo adoptado para la venta ambulante y autogestiva durante los meses iniciales del conflicto.

La persistencia de la exclusión de las tareas pesadas para las mujeres se vincula también con la reivindicación de las luchas previas tendientes a que los empresarios no impongan a las envasadoras labores que excedian las pautadas por el CCT para su puesto de trabajo.

28. Realizamos esta aclaración porque, al calcularse el pago de acuerdo a la producción, el monto total varía si se filetea mayor volumen de pescado en esa franja horaria. 
Finalmente, observamos un quiebre en la consideración de los patrones en relación con la concientización del carácter desigual en la relación entre capital y trabajo. Esta desigualdad fue comprobada al advertir la riqueza obtenida por los empresarios, palpable en el contexto de la crisis empresarial. En dicha crisis, mientras estos seguian disponiendo de recursos monetarios, hectáreas en terrenos cultivables y un vehículo oneroso, los obreros no habían cobrado salarios y corrian riesgo de quedarse sin trabajo. Esto se constata en los siguientes testimonios:

Siempre amenazaban con que iban a cerrar para que entendamos si se atrasaban en el pago de alguna quincena por equis motivo, te lloraban... cuando en realidad el que necesitaba era el trabajador, no ellos, con algo compraron el campo que tienen, una chata, una camioneta de más de cien lucas... (Julio, trabajador de La Recuperada 32 años) ${ }^{29}$

El tipo nos cagó, no nos pagó y todavía tratarlo bien viste... Y ahí cambió todo, cambió todo para nosotros con respecto a los patrones. (Dario, trabajador de La Recuperada 35 años) ${ }^{30}$

Julio: Más que nada que había gente que por las fiestas necesitaba un mango, y un compañero la vio a la Chola (una de las dueñas) en el supermercado con el carro lleno y nosotros nada.

Dario: Ellos sí se la guardaban y la tuvieron. El tema que a veces te pegaban una llorada bárbara que te daba ganas de salir a hacer una vaquita para prestarles plata... ${ }^{31}$

Ahora se trabaja todos juntos, todos iguales. Ahora repartimos las ganancias iguales, antes la patronal se quedaba con toda la torta, a nosotros nos pagaban lo que nosotros haciamos y siempre ellos llevándose su plata y los trabajadores siempre como trabajadores... Nosotros veníamos en bicicleta y el patrón en camioneta $4 \times 4 \ldots$ (Julián, trabajador de La Recuperada, 29 años $)^{32}$

Esta diferencia fundamental entre obreros y patrones es otro de los aprendizajes productos de las huelgas como escuelas de guerra, tal como lo explica Lenin:

29. Entrevista grupal a La Recuperada, realizada por la autora el 24 de octubre de 2011.

30. Ibídem.

31. Ibídem.

32. Entrevista a Julián, realizada por la autora el 30 de octubre de 2011. 
Ocurre muy a menudo que un patrón trata de engañar a todo trance a los obreros, de presentarse ante ellos como un bienhechor, de encubrir la explotación de sus obreros con una dádiva cualquiera, con cualquier promesa falaz. Cada huelga destruye siempre de golpe este engaño, mostrando a los obreros que su "bienhechor" es un lobo con piel de cordero. (Lenin, 2013: 7)

Los obreros enlazaron las vivencias de luchas previas, en las cuales el empresariado amenazaba con cerrar la planta y aducía que no poseía riqueza acumulada, con la situación actual, en la que producto de la inactividad en la planta solo los trabajadores eran empujados a la escasez. Esta conclusión se conjugó con la bronca generada por la deuda salarial, la falta de respuestas, el encontrarse de forma imprevista con la fábrica cerrada, el desentendimiento del pago de las indemnizaciones y las maniobras empresariales para impedir la conformación de la cooperativa de trabajo.

\section{Todo pasa y todo queda}

A partir de las espontáneas referencias de los trabajadores de La Recuperada hacia luchas anteriores al proceso de recuperación, se reconstruyó su impacto en el conflicto por la continuidad laboral. Observamos evidencia del carácter pedagógico de conflictos precedentes y cómo los mismos decantaron en potencialidad de este colectivo obrero para enfrentar al empresariado que amenazaba con dejarlos sin empleo y sin indemnizaciones. La colectividad fabril, la confianza en las propias fuerzas, la construcción de una moral obrera dispuesta a alzarse por sus derechos y la solidaridad de clase extendida a otros sectores obreros caracterizaron este proceso, y fueron producto de la puesta en juego de herramientas teóricas, metodológicas y prácticas que no surgieron de la nada, sino que se retrotraen a experiencias conjuntas anteriores que se relanzaron en 2011.

Asimismo, otros aspectos del bagaje de las luchas previas se retomaron una vez constituida la cooperativa de trabajo autogestiva. Se reorganizaron aspectos del régimen fabril y se cuestionó la división intraobrera que la patronal impuso en el proceso de trabajo y el tipo de contratación, mediante la anulación de mecanismos de precarización laboral de los tres grupos obreros más perjudicados por la gestión patronal: los eventuales, los peones y las envasadoras. La igualación de los ingresos, los tiempos y las tareas de trabajo (manteniendo la separación de las mujeres de las tareas pesadas, desde una perspectiva de cuidado del cuerpo femenino) fueron los dispositivos obreros para 
llevar a cabo tales transformaciones. Estas modificaciones muestran que, si las luchas previas ya habian anticipado conclusiones referidas al cuestionamiento en las divisiones hacia su interior, solo la gestión obrera pudo revertirlas desde una perspectiva igualitaria y democrática.

Finalmente, en la misma operación por la cual se apropiaron de los medios de producción, quienes conformaron La Recuperada alcanzaron mayor conciencia de la desigualdad en los términos de la relación entre capital y trabajo, de la diferencia entre la propiedad y la desposesión de los medios de producción, entre ganancia y salario.

Por todo ello, concluimos que, a la manera de escuelas de guerra, los combates previos a la recuperación fueron fundacionales de la misma, cobraron un sentido pedagógico retrospectivo y ampliaron el potencial clasista, al emerger sus conclusiones, prácticas, solidaridad y moral previamente alcanzadas. Al andar, los trabajadores de Industrial Pesquera hicieron camino, y de esta forma lograron imponer a la patronal la voluntad de continuar trabajando en la empresa, conservar su lugar y sus puestos de trabajo, golpe a golpe, verso a verso.

\section{Bibliografía}

Bertolotti, M., E. Erratzi y A. Pagani (1997), "Resultados preliminares del Censo Nacional Industrial Pesquero. Año 1996. Provincia de Buenos Aires. Plantas instaladas en tierra. Mar del Plata, Buenos Aires", Informe técnico interno, $\mathrm{n}^{\circ} 34$, INIDEP.

Brunet, I. y C. Pizzi (2011), Capitalismo y subjetividad obrera. El movimiento de empresas recuperadas en Argentina, Madrid: Biblioteca Nueva.

Collado, P. y S. Roitman (2015), "Más allá de la revitalización sindical: la subjetivación política de los trabajadores", en Marcelo Delfini y Juan Montes Cató (comps.), Recomposición del capital y respuestas sindicales ¿Hacia nuevas relaciones laborales?, Buenos Aires: UNGS, pp. 147-178.

Dinerstein, A. (2007) "Workers' factory takeovers and new state policies in Argentina: towards an "institutionalisation" of non-governmental public action?", Policy \& Politics, vol. 35, pp. 529-550.

Engels, F. (1974), La situación de la clase obrera en Inglaterra [1845], Buenos Aires: Esencias.

Federación de Trabajadores de Industrias de la Alimentación (2003), Convenio colectivo de trabajo $n^{\circ} 372 / 04$. Industrialización del pescado y subproductos de la pesca. Cámara Argentina Patagónica de Industrias Pesqueras y Cámara Industrial Pesquera y afines de Necochea, Buenos Aires, 30 de octubre de 2003.

Lenin, V. (2013), "Sobre las huelgas" [1899], en Obras selectas, t. I, Buenos Aires: Ediciones IPS, pp. 61-68.

Mateo, J.M., A. Nieto y G. Colombo (2010), "Precarización y fraude laboral 
en la industria pesquera marplatense. El caso de las cooperativas de fileteado de pescado. Estado actual de la situación y evolución humana de la rama, 1989-2010", en Concurso Bicentenario de la Patria, Premio Juan Bialett Massé, Buenos Aires: Ministerio de Trabajo de la Provincia de Buenos Aires, pp. 177-203.

Nogueira, M.L. (2013), "Deconstruyendo la organización interna en dos fábricas pesqueras recuperadas de Necochea y Quequén", ponencia presentada en las $V$ Jornadas Interdisciplinarias de Estudios Portuarios, organizada por la Red de Estudios Portuarios (REDEP), Quequén, Necochea, 6 al 8 de noviembre.

Pérez Álvarez, G. (2013), "Juego, resistencia y cultura obrera en la Patagonia Argentina: el fútbol ante contextos represivos", Nuevo Mundo Mundos Nuevos, disponible en http://journals.openedition.org/nuevomundo/65161.

Rebón, J. (2004), Desobedeciendo al desempleo. La experiencia de las empresas recuperadas, Buenos Aires: La Rosa Blindada y Picaso.

Ruggeri, A. (comp.) (2009), Las empresas recuperadas: autogestión obrera en Argentina y América Latina, Buenos Aires: Facultad de Filosofia y Letras. Zelaya, M. (2013), La cooperativización del trabajo en la industria del pescado marplatense, monografia, Mar del Plata: Facultad de Ciencias Económicas y Sociales. 